\title{
THE GENERALIZING WORK ON HISTORY AND CULTURE OF THE COSSACKS
}

\author{
(Book Review: Essays on the History and Culture of the Cossacks of Southern Russia: \\ Collective Monograph [Text] / ed. by G. G. Matishov, I. O. Tyumentsev ; \\ Southern Scientic Centre of the Russian Academy of Sciences ; \\ Volgograd Branch of Federal State Budgetary Educational Institution \\ of Higher Professional Education "Russian Presidential Academy \\ of National Economy and Public Administration". - Volgograd : \\ Izd-vo Volgogradskogo Filiala FGBOU VPO RANKhiGS, 2014. - 624 p.)
}

\author{
Nikolay F. Bugay \\ Doctor of Sciences (History), \\ Chief Researcher, Institute of Russian History of RAS, Professor, \\ Class 3 Active State Advisor of the Russian Federation \\ nikolay401@yandex.ru \\ Dmitriya Ulyanova St., 19, 117036 Moscow, Russian Federation
}

\begin{abstract}
This article represents a review of the collective monograph "Essays on the history and culture of the Cossacks of Southern Russia", published in 2014 under the auspices of the Southern Scientific Centre of the Russian Academy of Sciences and the Volgograd branch of Russian Presidential Academy of National Economy and Public Administration. The review provides a critical analysis of the material in the collective monograph on the problems of studying the history and culture of the Cossacks. The author notes that the revival of Cossacks that began in the 1990s, not only drew attention to the Cossack problem in modern Russia, but also stimulated scientific and public interest in the history and culture of the Cossacks.

Russian Cossacks have rich past and its culture is colorful and specific, its role in the history of Russia is significant. Issues of origin and development of the Cossacks, their place among the peoples of Russia, the specificity of cultural practices are constantly causing great interest for researchers. All this has led scientistsspecialists in the history and culture of the Cossacks to the idea of the creation of this scientific work, which has become a generalization of accumulated research experience on the most important issues of the Cossacks' historical existence. The authors of the monograph limited their research by Southern Russia because of the complexity of creating general work on all Cossack troops which have historically existed in the Russian state and had sometimes very great cultural differences and special historical destiny. The authors made a very successful attempt to highlight the main problematic aspects of the history and culture of the Cossacks. The genre of essay chosen for creating a collective monograph, has allowed not only to identify the most relevant topics of the Cossack history and culture, but also to consider them in relation and development. Each essay contains material that allows to identify the most important problems of different historical periods and various Cossack communities. Together, we get an idea not only about the history of the Cossacks, but also on the results of professional scientific developments in this area. Essays on the history and culture of the Cossacks of Southern Russia - work in which the efforts of its sponsors were systematically analyzed and the main existing today information and research materials on the history and culture of the Cossacks of Southern Russia were $\theta$ compiled into a single concept.
\end{abstract}

Key words: Cossacks of Southern Russia, culture of the Cossacks, Cossacks history, current state of the Cossacks, Cossacks history problems. 


\title{
ОБОБЩАЮЩИЙ ТРУД ПО ИСТОРИИ И КУЛЬТУРЕ КАЗАЧЕСТВА
}

\author{
(Рец. на кн.: Очерки истории и культуры казачества Юга России : \\ коллектив. моногр. [Текст] / под ред. Г. Г. Матишова, И. О. Тюменцева ; \\ Южный научный центр Российской академии наук ; Волгоградский филиал \\ ФГБОУ ВПО «Российская академия народного хозяйства \\ и государственной службы при Президенте РФ». - Волгоград : \\ Изд-во Волгоградского филиала ФГБОУ ВПО РАНХиГС, 2014. - 624 с.)
}

\section{Николай Федорович Бугай}

Доктор исторических наук, главный научный сотрудник Института российской истории РАН, профессор, действительный государственный советник III кл. Российской Федерации nikolay401@yandex.ru ул. Дмитрия Ульянова, 19, 117036 г. Москва, Российская Федерация

Аннотация. Представляемая статья - рецензия на коллективную монографию «Очерки истории и культуры казачества Юга России». Она была опубликована в 2014 г. Южным научным центром Российской академии наук и Волгоградским филиалом Российской академии народного хозяйства и государственной службы при Президенте Российской Федерации. В рецензии дается критический обзор материала в коллективной монографии, посвященного проблемам исследования истории и культуры казачества. Автор отмечает, что начавшееся в 1990-х гг. возрождение казачества не только привлекло внимание к казачьей проблеме в современной России, но и стимулировало научный и общественный интерес к истории и культуре казачества.

Казачество России имеет богатое прошлое, его культура колоритна и специфична, его роль в истории России весьма значительна. Вопросы возникновения и развития казачества, его роли и месте среди народов России, специфика культурных традиций постоянно вызывают живой интерес исследователей. Все вышесказанное привело ученых - специалистов по истории и культуре казачества к идее создания данного научного труда, который стал обобщением накопленного исследовательского опыта по наиболее важным проблемам исторического бытия казачества. Авторы коллективной монографии ограничились Югом России в силу сложности создания обобщающего труда по всем казачьим войскам, существовавшим исторически в российском государстве, имевшим подчас очень большие культурные различия и особую историческую судьбу. Однако при этом им удалось сделать весьма успешную попытку освещения в своей работе основных проблемных аспектов истории и культуры казачества. Жанр очерков, избранный при создании коллективной монографии, позволил не только определить наиболее актуальные темы казачьей истории и культуры, но и рассмотреть их во взаимосвязи и развитии. В каждом очерке содержится материал, позволяющий определить наиболее важные проблемы разных исторических периодов и разных казачьих сообществ. Все вместе позволяет получить представление не только о казачьей истории, но и об итогах профессиональных научных разработок в данной сфере. «Очерки истории и культуры казачества Юга России» - труд, в котором стараниями его авторов были систематизированы, проанализированы и собраны в единую концепцию основные существующие на сегодня информационно-исследовательские материалы по истории и культуре казачества Юга России.

Ключевые слова: казачество Юга России, культура казачества, история казачества, современное состояние казачества, проблемы истории казачества.

Трансформации, которые претерпело российской сообщество в последние два десятилетия, вызвали коренные перемены и в процессе возрождения, по определению Закона РСФСР «О реабилитации репрессированных народов» (26 апр. 1991 г.), казаков как культурно-этнической общности людей [10, с. 74]. Этим законом было впервые дано и научное определение казачеству, что, конечно, не может быть истиной в последней инстанции, тем 
не менее позволяет учитывать это определение в качестве общего знаменателя в ходе исследований темы в целом и в практике повседневности.

Начало 1990-х гг. было отмечено небывалым повышением уровня этнической мобильности среди многих этнических общностей российской государственности, их натурализации. Не могли они оставить в стороне этого потока и казачье население, которое находилось в СССР в особых специфических условиях, особенно в плане их этнической мобилизации и натурализации.

Эти события уже сами по себе привлекают внимание. Появляется возможность рассмотреть, каким же образом преображались различные стороны этой группы населения применительно к Российской Федерации. Известно, что группы казачьего населения оказались и на территории других возникших на базе бывшего СССР самостоятельных государств - Казахстана, Белоруссии, Украины.

Территориальный разброс казачьих войск по приграничным территориям Российской империи придавал специфике дополнительный фактор, а именно периферийность, местный колорит. Различные казачьи сообщества, сформировавшиеся на территории России, оказались разбросанными от Хабаровского края до Северного Кавказа.

Как показала практика последующего времени, казачьи объединения при этом имели единые цели и задачи, которые государство ставило перед казаками. Правда и разнились они условиями концентрации, уровнем оказываемого влияния на социо- и этнокультурную природу российских казачьих общественных объединений. Именно так они стали именоваться после принятия Закона РФ «Об общественных объединениях Российской Федерации» (1995 год).

Несмотря на обилие исследований по истории и культуре казачества $[2 ; 4 ; 5 ; 6 ; 7 ; 11$ и др.], обобщающих трудов в этом направлении, охватывающих всю проблематику развития казачьих сообществ и дающих целостное представление о многообразной и противоречивой истории российского казачества, нет. Тому есть и объективные, и субъективные причины.
Одним словом, благодаря российскому казачеству в исторической науке сформировалось одно из важных ее территориальных направлений - периферийное, пограничное. Оно требует и самостоятельного изучения, и осмысления, что, несомненно, позволит пополнить наши познания об этом феномене российской государственности.

Корни казачества уходят в далекое прошлое, и вопросы возникновения, эволюции казачества постоянно интересуют и привлекают ученый мир. Этот интерес проявляется и со стороны общества. Все это не может не усиливать актуальность проблемы в целом, особенно в связи с процессами возрождения казачества в 1990-е годы. В этом важной составляющей стал перевод существования казачества из вербального состояния, упоминания о казачестве только в воспоминаниях, песнях в правовую плоскость. Об этом свидетельствует огромная работа, проведенная за два с половиной десятилетия по формированию правовой базы процессов, происходящих как внутри казачества, так и непосредственно в отношениях между казачеством и государственными структурами, во взаимодействии казачества с другими этническими общностями на территории России, в ее новом формате как существующего самостоятельно государства [3; 9 и др.].

Таким образом, единообразие формировавшейся административно-управленческой системы казачьих войск, задаваемое политико-государственными условиями в 1990-х гг., потребовало формирования экономического сектора и вовлечения в него казачества, наполнения его жизнеобустройства разнообразным социокультурным содержанием, прежде всего путем взаимодействия казачьей культуры с культурами других народов. С учетом малого накопления материала пока решить эту задачу в научном плане остается трудной задачей.

Развитие Российской государственности подтверждает со всей очевидностью, насколько важно в многонациональном сообществе на всех этапах его истории, включая и период 1990-х - 2015 гг., отслеживание ситуации именно с духовным состоянием общества. Духовность казачества накрепко увязана с восприятием им окружающего мира, 
а также с тем, с кем человек себя идентифицирует. Это особенность проявилась в ходе проводившейся Всероссийской переписи населения 2002 года. Более 140 тыс. граждан назвали себя казаками России, впервые за долгие годы почувствовали себя, как и все этнические общности России, единым многонациональным российским народом. Это находит отражение в Основном законе государства Конституции Российской Федерации.

В одной из своих публикаций министр Российской Федерации В.А. Михайлов заметил: «Кавказ - единый геополитический регион. И принести туда мир и спокойствие может только культура. Альтернативы просто не существует» [8, с. 10]. Несомненно, эта функция остается и за казачьей культурой как органичной составляющей культур народов Кавказа.

Казачество России как население со своей спецификой, менталитетом отличается богатой творческой культурой, включающей в себя такие компоненты, как хоровое пение (певческая культура), танцевальное и другие виды творчества. Бесспорно, это дает возможность обеспечить нарушенную этнокультурную межпоколенную связь, усилить стремление к сохранению казачьих семейных традиций, одежды, кухни, церковных обрядов.

Авторы представляемой коллективной монографии ограничились только регионами Юга России, но при этом сделали, по нашему мнению, успешную попытку освещения в своей работе основных проблемных аспектов истории и культуры казачества. Создатели рецензируемого труда признают, что даже при таком редуцированном подходе охватить все проблемы истории казачества невозможно. Несомненно, это предопределило избрание постановки задачи в предлагаемом способе изложения, определение наиболее актуальных тем казачьей истории и культуры, рассмотрение их в тесной взаимосвязи и развитии.

Избрание проблемно-хронологического подхода с отчетливым тематическим разделением авторских статей сказалось на структуре работы. Монография разделена на две части, одна из которых - это исторические очерки, вторая - очерки по традиционной культуре казачества. По проблемно-хронологическому принципу сгруппированы и статьи в очер- ках. В каждом из них содержится материал, позволяющий определить наиболее приоритетные проблемы разных исторических периодов и разных казачьих общественных объединений. Все вместе позволяет получить представление не только о казачьей истории, но и об итогах профессиональных научных разработок в изучаемой сфере.

Первая, историческая, часть открывается очерком, посвященным средневековой истории казачества. Здесь представлены материалы таких известных специалистов по ранней истории казачества, как Н.А. Мининков, И.О. Тюменцев, С.А. Голованова. В их разделах анализируются основные проблемные темы в истории казачества XV-XVII веков. Это основные версии относительно начала казачьей истории, происхождения казачества, формирования казачьих сообществ на Дону и Тереке, процесса включения казаков в систему Московского царства, участия казаков в событиях Смутного времени. Большого внимания заслуживает и материал о развитии вольного и служилого казачества в Поволжье Е.В. Кусаиновой.

По нашему мнению, особая ценность этого очерка заключается в том, что авторы смогли обобщить все спорные моменты казачьей истории этого периода и дать представление как о противоречивом развитии казачьих обществ в этот период, так и о сложности исторического поиска, проблеме источников в историческом исследовании.

Ключевой темой следующего очерка, охватившего период с XVIII до первой половины XIX в., стала интеграция казачьих войск в систему Российского государства и связанные с этим процессом проблемы, повлекшие за собой конфликт между казаками и имперской властью. Она подана как итог существующих традиционных взглядов. В очерке представлены материалы таких известных специалистов, как А.И. Агафонов, Д.В. Сень, Н.Н. Великая, Б.Е. Фролов, В.А. Колесников, А.В. Курышев, И.В. Торопицын.

На период XVIII - начала XIX в. приходятся кардинальные перемены в судьбе казачества. По мнению А.И. Агафонова, начало XVIII в. на Дону было связано, прежде всего, с событиями периода восстания С. Разина и реакцией власти на эти события. Былые 
вольности и мечтания казаков о социальном равенстве уходили в прошлое, казачество постепенно становится частью социально-политической системы Российского государства. О том, как реагировали казаки на ужесточение государственного контроля, то протестуя вплоть до ухода на территории других государств, то с готовностью определяя себя слугами России, повествуют материалы этого очерка.

Третий очерк исторический части монографии раскрывает сложные процессы, происходившие в казачьей среде во второй половине XIX - начале XX века. Центральная идея этой части рецензируемых очерков - кризис территориально-сословной системы казачества. Казачество, по замечанию О.В. Матвеева, «стало развиваться гораздо шире определенных ему сословных рамок» (с. 215), и, как констатирует автор, это подтверждается и новыми архивными находками.

Модернизация, происходившая в России, меняла привычные условия жизни казачества, с одной стороны, вовлекая его в новые социально-политические процессы. С другой стороны, как отметил А.А. Волвенко, за казачество разворачивалась настоящая борьба как со стороны государства, нуждающегося в казаках в качестве охранительной силы, так и со стороны оппозиционных сил революции (противостоявшая контрреволюция), стремящихся «перетянуть» казаков на свою сторону.

Среди авторов статей последующего очерка - А.А. Волвенко, О.В. Матвеев, Н.Н. Великая, И.В. Торопицын. Материалы третьего очерка позволяют увидеть как изменение условий существования казачества, вызванного победой революции, так и изменение его внутренних традиционных установок, начавшуюся трансформацию его установленного порядка существования.

В очерке, представленном разделами, подготовленными В.П. Трутом, А.В. Венковым и О.В. Рвачевой, раскрыты трагические события начала XX в. (Первая мировая война, революции и Гражданская война) в истории казачества. Структура очерков позволяет проследить, как казачество, отдавшее огромное количество сил в период Первой мировой войны, последовательно исполнявшее свой военный и гражданский долг перед Отечеством, оказалось на революционном перепутье, а потом втянутым в события Гражданской войны. Она-то и стала важнейшим этапом казачьей истории, перекроившим всю систему казачьего мира. Гражданская война переломный момент в истории казачьих сообществ Юга России. В книге она рассматривается с различных сторон: и как военные события, и как попытка строительства собственной автономной государственной системы на Юге России. Уже вначале 1920-х гг. казачеству со стороны большевиков был нанесен заметный ущерб.

В центре внимания авторов оказались и ключевые периоды исторического существования казаков в системе советского государства, а именно когда изменялась судьба казачьих сообществ. Социалистическая модернизация трансформировала саму суть казачества. В итоге оно было превращено частично в крестьянское население России. Однако военный потенциал казачества оказался востребованным и в условиях Великой Отечественной войны. После этого казаки надолго ушли с исторической сцены, чтобы вновь появиться на ней в конце XX в., в период формирования нового российского государства. Авторами последнего очерка выступили ученые А.П. Скорик, Е.Ф. Кринко, А.Г. Масалов, О.В. Рвачева.

Объемная часть труда посвящена традиционной культуре казачества Юга России. В ней представлены статьи ведущих специалистов в области этнографии и истории культуры казачества, таких как Т.С. Рудиченко, М.А. Рыблова, Н.И. Бондарь, И.В. Торопицын.

Привлекает своим содержанием статья, в которой раскрывается, как и в каких условиях складывалась традиционная культура казаков Юга России, что было оказано влияние фронтирной территории на культурную модель казачества; показаны трансформации культурной системы казаков, связанные с кризисными и деструктивными ситуациями. В статье исследуются основные принципы формирования и организации ранних казачьих сообществ, их потестарная структура, раскрыты источники существования и жизнеобеспечения. В последующих очерках выявлена специфика традиционной культуры всех казачьих сообществ Юга России. 
Структура всех очерков второй части единообразна. Она основана на рассмотрении ключевых элементов, на которых строилась система традиционной культуры казаков - это поселения и жилища, традиционные комплексы одежды, обряды жизненного и календарного циклов, являющиеся ярким проявлением культуры казачества, фольклор. Такое построение очерков позволяет проследить специфические культурные черты каждого казачьего сообщества на Юге России, а также выявить схожесть культурных черт и процессов, влияющих на развитие культуры казачества.

Развитие культуры казачества Юга России рассматривается в основном на материалах XIX-XX веков. Такой выбор хронологических рамок, по-видимому, был обусловлен как источниковыми возможностями, так и тем, что к XIX в. традиционная культура казачества приобрела устойчивые черты, связанные с военно-служилым характером их деятельности.

Однако шестой и седьмой по счету очерки посвящены весьма интересной и нетривиальной проблеме - трансформации казачьей культуры в советской системе (очерк шестой) и в постсоветское время, связанное с казачьим возрождением, появлением феномена казачества в современных российских реалиях.

Однозначно, самобытная культура казачества должна расширять свои горизонты при активной поддержке государственных структур и при непосредственной помощи самих общественных казачьих объединений. Она пока переживает период, который можно было бы выразить словами - «из тени в свет перелетая», однако постепенно становится массовой и воспринимаемой. А в сочетании с культурами народов, проживающих совместно с казаками, она обогащается новыми красками, становится еще более колоритной, насыщенной и содержательной.

Несомненно, этот процесс беспрерывный и он возможен только в условиях консенсуса и взаимопонимания, уважения и соработничества.

Таким образом, рецензируемые «Очерки истории и культуры казачества Юга России» - труд, в котором стараниями его авторского коллектива систематизированы, проанализированы и собраны в единую концепцию основные существующие на настоящий период информационно-исследовательские мате- риалы по истории и культуре казачества Юга России. Их изучение позволило авторам очерков, с одной стороны, выработать единый подход к изложению материала, а именно - рассмотреть историю казачества через призму кризисных этапов его существования. С другой - этот же подход привел к тому, что ряд важных исторических сюжетов, таких как казачья эмиграция 1920-х гг. или казачий коллаборационизм, не нашел должного отражения в очерках.

Основное внимание в очерках (прежде всего в их исторической части) уделено все же процессам формирования социальных и политических структур казачьих войск. Авторы очерков достаточно традиционны в своих исследовательских подходах к изучению истории казачества.

С учетом того, что целью создания настоящих очерков выступало своеобразное обобщение многочисленных исторических исследований и подведение промежуточных итогов профессиональных научных разработок в области казачьей истории и культуры, и об этом авторы предупреждали читателей во вступительной статье, изложенные замечания можно отнести скорее в область пожеланий. Такой подход остается просто выражением надежды на то, что в следующих подобных очерках найдут отражение и другие незатронутые сюжеты и проблемы казачьей истории.

\section{СПИСОК ЛИТЕРАТУРЫ}

1. Бахвалова, В. А. Традиционная культура Донского казачества (по материалам фольклора) : автореф. дис. ... канд. ист. наук / Бахвалова Валентина Александровна. - Волгоград, 2009. - 24 с.

2. Бугай, Н. Ф. Северный Кавказ: границы, конфликты, беженцы. Документы, факты, комментарии / Н. Ф. Бугай, А. М. Гонов. - Ростов н/Д. : РВШ МВД РФ, 1997.

3. Бугай, Н. Ф. Корейцы Юга России: межэтническое согласие, диалог, доверие / Н. Ф. Бугай. М. : ИЦ Ин-та рос. истории РАН, 2015. - 512 c.

4. Бухтияров, М. Н. Зарождение и становление донской казачьей интеллигенции (XVIII в. - начало 60 -х годов XIX в) : автореф. дис. ... канд. ист. наук / Бухтияров Максим Николаевич. - Ростов н/Д., 2010. $-22 \mathrm{c}$.

5. Голованова, С. А. Казачество Терека и Кубани: этнополитические и культурно-исторические 
особенности становления и эволюции : автореф. дис. ... д-ра ист. наук / Голованова Светлана Александровна. - М., 2005.- 52 с.

6. Гонов, А. М. Северный Кавказ: актуальные проблемы русского этноса (20-30-е годы) / А. М. Гонов. - Ростов н/Д. : РВШ МВД, 1997.

7. Матвеев, О. В. Историческая картина мира Кубанского казачества: особенности военно-сословных представлений (конец XVIII-начало XX в.) : автореф. дис. ... д-ра ист. наук / Матвеев Олег Владимирович. -Ставрополь, 2009. $-53 \mathrm{c}$.

8. Михайлов, В. А. Дистанцию между культурами надо сокращать / В. А. Михайлов // Этносфеpa. - 2001. - № 11 (83).

9. Попова, Ю. Н. Корейская диаспора Краснодарского края: историко-культурные аспекты (XX - начало XXI века) : автореф. дис. ... канд. ист. наук / Попова Юлия Николаевна. - Краснодар, 2004. $-23 \mathrm{c}$.

10. Реабилитация народов России. Сборник документов. - М. : Инсан, 2000. - 447 с.

11. Хотина, Ю. В. Формирование историкокультурного наследия Кубани в конце XVIII - начале XX в. : автореф. дис. ... канд. ист. наук / Хотина Юлия Васильевна. - Краснодар, 2006. - 23 с.

\section{REFERENCES}

1. Bakhvalova V.A. Traditsionnaya kultura Donskogo kazachestva (po materialam folklora): avtoref. dis. ... kand. ist. nauk [Traditional Culture of the Don Cossacks (on Folklore Materials). Cand. hist. sci. abs. diss.]. Volgograd, 2009. 24 p.

2. Bugay N.F., Gonov A.M. Severnyy Kavkaz: granitsy, konflikty, bezhentsy. Dokumenty, fakty, kommentarii [North Caucasus: Borders, Conflicts, Refugees. Documents, Facts, Comments]. Rostov-onDon, RVSh MVD RF Publ., 1997.

3. Bugay N.F. Koreytsy Yuga Rossii: mezhetnicheskoe soglasie, dialog, doverie [Koreans of the South of Russia: Interethnic Consent, Dialogue, Trust]. Moscow, ITs In-ta ros. istorii RAN, 2015. $512 \mathrm{p}$.
4. Bukhtiyarov M.N. Zarozhdenie i stanovlenie donskoy kazachyey intelligentsii (XVIII v. - nachalo 60-kh godov XIX v): avtoref. dis. ... kand. ist. nauk [Origin and Formation of the Don Cossack Intellectuals (18th Century-Early 1860). Cand. hist. sci. abs. diss.]. Rostov-on-Don, 2010.22 p.

5. Golovanova S.A. Kazachestvo Tereka $i$ Kubani: etnopoliticheskie i kulturno-istoricheskie osobennosti stanovleniya i evolyutsii: avtoref. dis. ... $d$-ra ist. nauk [Cossacks of Terek and Kuban: Ethnopolitical, Cultural and Historical Features of Formation and Evolution. Dr. hist. sci. abs. diss.]. Moscow, 2005. $52 \mathrm{p}$.

6. Gonov A.M. Severnyy Kavkaz: aktualnye problemy russkogo etnosa (20-30-e gody) [North Caucasus: Modern Problems of the Russian Ethnos (1920s-1930s)]. Rostov-on-Don, RVSh MVD Publ., 1997.

7. Matveev O.V. Istoricheskaya kartina mira Kubanskogo kazachestva: osobennosti voennososlovnykh predstavleniy (konets XVIII - nachalo $X X$ v.): avtoref. dis. ... d-ra ist. nauk [Historical Worldview of the Kuban Cossacks: Features of Military and Class Representations (End of 18th Beginning of 20th Century). Dr. hist. sci. abs. diss.]. Stavropol, 2009. 53 p.

8. Mikhaylov V.A. Distantsiyu mezhdu kulturami nado sokrashchat [The Distance Between Cultures Should Be Reduced]. Etnosfera, 2001, no. 11 (83).

9. Popova Yu.N. Koreyskaya diaspora Krasnodarskogo kraya: istoriko-kulturnye aspekty (XX-nachalo XXI veka) : avtoref. dis. ... kand. ist. nauk [Korean Diaspora of the Krasnodar Region: Historical and Cultural Aspects (20th - Beginning of the 21st Century). Cand. hist. sci. abs. diss.]. Krasnodar, 2004. 23 p.

10. Reabilitatsiya narodov Rossii. Sbornik dokumentov [Rehabilitation of the Russian Peoples. Collection of Documents]. Moscow, Insan Publ., 2000. $447 \mathrm{p}$.

11. Khotina Yu.V. Formirovanie istorikokulturnogo naslediya Kubani v kontse XVIII nachale $X X$ v.: avtoref. dis. ... kand. ist. nauk [Formation of Historical and Cultural Heritage of Kuban at the End of 18th - Beginning of the 20th Century. Cand. hist. sci. abs. diss.]. Krasnodar, 2006. 23 p. 